\title{
Multiband modulation spectroscopy for determination of sex and species of mosquitoes in flight
}

Gebru, Alem; Jansson, Samuel; Ignell, Rickard; Kirkeby, Carsten Thure; Prangsma, Jord C.; Brydegaard, Mikkel

Published in:

Journal of Biophotonics

Link to article, DOI:

10.1002/jbio.201800014

Publication date:

2018

Document Version

Peer reviewed version

Link back to DTU Orbit

Citation (APA):

Gebru, A., Jansson, S., Ignell, R., Kirkeby, C. T., Prangsma, J. C., \& Brydegaard, M. (2018). Multiband modulation spectroscopy for determination of sex and species of mosquitoes in flight. Journal of Biophotonics, 11(8), [e201800014]. https://doi.org/10.1002/jbio.201800014

\section{General rights}

Copyright and moral rights for the publications made accessible in the public portal are retained by the authors and/or other copyright owners and it is a condition of accessing publications that users recognise and abide by the legal requirements associated with these rights.

- Users may download and print one copy of any publication from the public portal for the purpose of private study or research.

- You may not further distribute the material or use it for any profit-making activity or commercial gain

- You may freely distribute the URL identifying the publication in the public portal 


\title{
Multiband modulation spectroscopy for determination of sex and species of mosquitoes in flight
}

\author{
Alem Gebru* ${ }^{1^{1-3}}$, Samuel Jansson ${ }^{2,3}$, Rickard Ignell ${ }^{4,}$ Carsten Kirkeby ${ }^{1,5}$, Jord C. Prangsma ${ }^{1}$ and Mikkel Brydegaard ${ }^{*-3,6}$ \\ ${ }^{I}$ FaunaPhotonics APS, Ole Maaløes Vej 3, 2200 Copenhagen, Denmark. \\ ${ }^{2}$ Lund Laser Centre, Department of Physics, Sölvegatan 14, SE-223 62, Lund, Sweden. \\ ${ }^{3}$ Centre for Animal Movement, Department of Biology, Lund University, Sölvegatan 37, SE-223 62, Lund, Sweden. \\ ${ }^{4}$ Chemical Ecology Unit, Department of Plant Protection Biology, SLU, Sundvägen 14, 23053 Alnarp, Sweden. \\ ${ }^{5}$ National Veterinary Institute, Technical University of Denmark, Bülowsvej 27, 1870 Frederiksberg C, Denmark. \\ ${ }^{6}$ Norsk Elektro Optikk AS, Prost Stabels vei 22, 2019 Skedsmokorset, Norway. \\ *Corresponding authors: alemkn@gmail.com, mikkel.brydegaard@fysik.lth.se
}

Keywords: Disease vectors, Species classification, Modulation spectroscopy,

Entomological lidar, Wing interference patterns

\section{Short title: Multiband modulation for mosquito species recognition.}

\begin{abstract}
:
We present a dual-wavelength polarimetric measurement method to distinguish species and sexes of disease transmitting mosquitoes in flight. By measuring co- and de-polarized backscattered light at 808 and $1550 \mathrm{~nm}$, the degree of linear polarization, wingbeat frequency, reflectance, spectral ratio and glossiness of mosquitoes can be retrieved. Body and wing contributions to these signals can be separated. Whereas the optical cross-section is sensitive to the aspect of observation, thus the heading direction of the insect in flight, we demonstrate that polarimetric- and spectral- band ratios are largely invariant to the aspect of observation. We show that wing glossiness, as well as wing-and body-spectral ratios are particularly efficient in distinguishing Anopheles coluzzii and Anopheles arabiensis, two closely related species of malaria vectors. Spectral- and polarimetric ratios relate to microstructural and melanization features of the wing and body of these species. We conclude that multiband modulation spectroscopy is a useful expansion of the parameter space that can be used to improve specificity of entomological lidars.
\end{abstract}

This article has been accepted for publication and undergone full peer review but has not been through the copyediting, typesetting, pagination and proofreading process, which may lead to differences between this version and the Version of Record. Please cite this article as doi: 10.1002/jbio.201800014 


\section{Surveillance of disease vectors}

Well into the $21^{\text {st }}$ century, vector-borne diseases persist to be a significant challenge to the global public health[1], not least in the tropical regions[2]. In particular malaria, caused by the Plasmodium falciparum parasite and transmitted by anophelines, places the mosquito as the most lethal animal in the world, claiming roughly a half million human lives yearly[3]. Tackling this distress requires both medical treatment by affordable drugs, rapid realistic medical diagnostics and prevention. Prevention methods include landscape drainage, spraying, urban planning and bed nets, and constitute the primary action in defeating the disease[4]. A significant problem is, however, the swift adaptation of both the parasite and the mosquito vector. Recently, drug resistant parasites have emerged across sub-Saharan Africa[5] and national campaigns of bed nets have been shown to shift the temporal niche of mosquitoes to earlier hours in the evening[6,7]. To improve available intervention methods, it is considered that accurate knowledge of the population dynamics and fluxes in the landscape can be the key to eliminate malaria and other vector borne infectious diseases on the African continent[8-10]. It is, however, not trivial to capture the illusive ecology and life stages of mosquitoes in a quantitative manner. Activity and aerial abundance of a mosquito species are highly weather sensitive and can change several orders of magnitude in just half an hour$[11,12]$. Moreover, preferred habitats for breeding and mating swarms can be confined to plants and tiny landmarks within a few meters[13-15].

To assess the population dynamics of mosquitoes, researchers have used sweep nets from vehicles[16], light traps[17], e-traps[18,19], kairomone and $\mathrm{CO}_{2}$ traps[20,21], as well as human bait[22-24]. Each method is known to be biased towards species, sexes or life stages, and investigations with extensive temporal and spatial coverage can be overwhelmingly labor intensive. In addition, the means for tracking mosquito fluxes and estimating dispersal are limited. Even if powder tagging[25,26] could be conducted, mark and release studies on 
anophelines is often unfeasible for ethical reasons. While it is feasible to indirectly correlate preferred mosquito habitats with geospatial information, such as satellite images or airborne topographic lidar[27,28], the sample rate is in best case weeks when cloud-free. As a result, such methods cannot capture a detailed description of the diurnal activity- and flux patterns, for example in the landscape surrounding an African village.

In recent years, our group[29] and others[30] have developed direct insect surveillance by remote modulation spectroscopy and entomological lidar[29,31,32]. We have discussed target classification by size[12,33] and oscillatory properties[34]. We have developed both lidar and dark-field methods with multiple spectral-[35,36] and polarization[37] bands. In this report, we present the prospects for discriminating species and sexes of disease vectors by multiple wavelength- and polarization bands. We report on a controlled laboratory experiment compatible with recent developed entomological lidars.

\section{Lidar light-mosquito interaction}

In this section we will briefly revise the photonic interrogation mechanism necessary to interpret our results. Non-intrusive and non-perturbing insect optical surveillance is preferably accomplished by near- or short-wave infrared wavelength for minimal absorption, this reduce influence through insect vision, heat sensing and photo-acoustics. In this study we have applied $808 \mathrm{~nm}$ and $1550 \mathrm{~nm}$, these bands are common laser wavelength which have been implemented in entomological lidar[29,36]. The $808 \mathrm{~nm}$ band can be absorbed by melanin and the $1550 \mathrm{~nm}$ can be absorbed by liquid water. Other feasible bands include 980 $\mathrm{nm}$, the longest band which can be detected by low-cost Si-CMOS. Such band could be applied in combination with $808 \mathrm{~nm}$ band for differentially indexing melanin. In the shortwave infrared, $1320 \mathrm{~nm}$ exhibit maximal backscatter for insects[38] and could be applied for 
absolute sizing, $1450 \mathrm{~nm}$ coincide with water absorption band and could be applied in combination $1320 \mathrm{~nm}$ to evaluate body surface.

Entomological lidars[30,31,34,37] detect insects transiting the probe volume with $\mathrm{kHz}$ sampling rates. The optical signatures retrievable to entomological lidars are foremost backscattering and in the ideal case also extinction. Lidar insect observations can be decomposed to a low frequency envelope originating from the insect body and an oscillatory part originating from the wings[32]. Polarimetric lidar[37,39,40] further allows decomposition of the specular and diffuse backscatter. Below we will revise how backscattered lidar light is affected by mosquito body and wings respectively.

\subsection{Body scatter contribution}

The non-oscillatory scatter contribution from the body can be encountered by a sliding minimum norm with the width of the wing beat period[32], this filter effectively extinguish the oscillatory part. The body time series describes the envelope of the insect moving through the probe volume[32]. For horizontal lidar transects, e.g., for evaluating species close to ground in relation to ground topography, the optical cross-sections (OCS), $\sigma$, can also be used to distinguish species by size[12,33]. This parameter is, however, largely affected by the flight direction, aspect of observation[34], and position in a non-tophat beam profile. For the mosquito species presented here, a significant part of the non-oscillatory scatter is also contributed by the specimens long hind legs and plumose antennae of the males.

Light interaction with the biological tissue in the mosquito thorax and abdomen is governed by photon-migration[41]. The anisotropic factor, g, is close to $\sim 95 \%$ for all known tissues in the NIR-SWIR range[42], the highest reported scatter coefficients for wet tissues in the NIR-SWIR are $\sim 30 \mathrm{~cm}^{-1}$ at $808 \mathrm{~nm}$ and $\sim 20 \mathrm{~cm}^{-1}$ at $1550 \mathrm{~nm}[42]$. Insects are, however, known to produce bright white markings by organising chitin-air matrices in their cuticle[43]. 
Such scatter coefficients reach values beyond $6600 \mathrm{~cm}^{-1}$, similar findings could also be the case for the white marks of Aedes mosquitoes.

Liquid water[44], present in the body, absorbs only SWIR light such as $1550 \mathrm{~nm}$. The water absorption dip magnitude will depend on the body tissue scatter coefficient[42], and an average photo migration path length of $\sim 500 \mu \mathrm{m}$ (mean penetration depth of $\sim 250 \mu \mathrm{m}$ ) would reduce diffuse $1550 \mathrm{~nm}$ reflectance to half. The reflectance in a $1320 \mathrm{~nm}$ band would, however, be largely unaffected by both melanin and water. Melanin is encountered in the cuticle, the absorption scales with $\lambda^{-3.4}$, and only bands below $1200 \mathrm{~nm}$, such as $808 \mathrm{~nm}$ are affected[42]. All mosquitoes are melanised to some extent and melanisation may differ even between closely related species[45]. In general, for all insects, the head with the compound eyes display highest melanisation. However, for mosquitoes, such as malaria vectors, the eyes are small compared to the body and melanisation could display minor variance among projections.

Diffusion theory[41] with scatter coefficients of $\sim 20 \mathrm{~cm}^{-1}$ implies mean penetration depths of $\sim 20 \mathrm{~mm}$ at $808 \mathrm{~nm}$ and $\sim 0.4 \mathrm{~mm}$ at $1550 \mathrm{~nm}$, with corresponding mean path lengths of $\sim 160 \mathrm{~mm}$ and $\sim 3 \mathrm{~mm}$, respectively. Whereas diffuse reflectance would account for $70 \%$ at $808 \mathrm{~nm}$ and just $3 \%$ at $1550 \mathrm{~nm}$, in practice, diffuse reflectance at $808 \mathrm{~nm}$ is attenuated by melanin to some $5-6 \%$, (see e.g.[38]). Because the mean free path is comparable to the organism size of mosquitoes ( ø1 mm), diffusion theory applies poorly and a better paradigm is that of random walks from a Monte Carlo perspective[46].

Because scattering is low compared to the organism, the entire mosquito body is flooded with photons both at $808 \mathrm{~nm}$ but even at $1550 \mathrm{~nm}$. Therefore, the light incidence angle only has a marginal influence on the diffuse photon flux distribution in the mosquito's body. Mosquitoes are rather transparent and much of the light is ballistic and co-polarized 
backscatter from the many layers or cuticles and organs throughout the body, and that this contribution dominates the diffuse contributions.

In general, absorption requires a tissue path length, and the mean path length is longer for depolarized backscatter than for co-polarised backscatter. Melanisation is often considered as an epidermal shell covering the tissue, therefore melanin is thought to influence the diffuse reflectance as a linear gain factor[47]. This understanding is simplified, and in practice melanin will foremost supress the diffuse NIR reflectance, whereas it can in some cases increase the specular NIR reflectance because melanin has a high refractive index[48] of $\sim 2$. Structured cuticles, such as the markings on Aedes species, on the other hand, would both depolarize light by multiple scatter and also shield the wet tissue and inhibit absorption of $1550 \mathrm{~nm}$ light. Thus, body Degree-of-Linear-Polarization at $1550 \mathrm{~nm}\left(\mathrm{DoLP}_{1550}\right)$ primarily reports on the surface and tissue texture. Exposed abdomen cuticles would both maintain polarization and leave wet tissue exposed to the light whereby the diffuse $1550 \mathrm{~nm}$ light could be absorbed by liquid water.

We conclude that the backscattered DoLP from mosquitoes can report both on the tissue and surface texture such as scales but also on absorbers such as melanin and liquid water for $808 \mathrm{~nm}$ and $1550 \mathrm{~nm}$ respectively.

\subsection{Wing scatter contribution}

The oscillatory contribution from the wings, is primarily governed by the wing beat frequency[49], WBF, or fundamental frequency, $f_{0}$, present in all wavelengths and polarizations in backscatter[34] and extinction[50]. The $f_{0}$ is sensitive to temperature and payload such as blood meals[51]. WBF correlate with wing area[52], span of the wing and body mass and is also affected by the humidity, wind speed, flight speed and acceleration[53,54]. WBF alone is often considered insufficient for species classification[55] although this may apply less to mosquito species that have a very high pitch[49]. However, 
the detailed oscillatory waveform is described by a harmonic spectrum, and it has been demonstrated multiple times that species could be discriminated by algorithms from the speech recognition community based on the harmonic content $[50,56,57]$. The harmonic tone line width and shape is given by the convolution with the body envelope and thus limited by probe volume transit time[32].

Recording of modulation spectra with diffuse, depolarized or extinguished light result in a handful detectable overtones, whereas recordings of insects with glossy wings using collimated, co-polarized backscatter can result in more than thirty detectable tones if instrument bandwidth allows it. Because harmonic tones or frequency side lobes (from an insect transiting a tophat beam profile), the fundamental frequency is not necessarily the strongest frequency component[34], and its identification is not trivial.

Mosquito wings can mainly be considered a glossy clear film of chitin[58] with membrane thickness in the order of 300-600 nm. In this range, chitin membranes of 395 and $659 \mathrm{~nm}$ thickness interfere constructively in backscatter for $808 \mathrm{~nm}$ lidar bands, whereas membranes of 254 and $764 \mathrm{~nm}$ produce backwards resonance with $1550 \mathrm{~nm}$ light. Correspondingly, destructive interference is observed for intermediate thicknesses. It is understood that the differential magnitude of the specular wing reflex in two bands is highly sensitive to membrane thickness. Membrane thicknesses have previously been used to discriminate closely related species[59,60].

The refractive index of some insects wing is age dependent, and this information could be used to determine the age of insects[61-63]. When specular spikes are observed, their intensity magnitude is largely insensitive to the aspect of observation since specular reflections from a glossy wing only occur when the surface normal of the wing coincide with the optical axis in backscatter detection. Specular flashes from glossy peaks are also discussed in[34,37]. 
Wings of Aedes aegypti and Culex quiquefasciatus are mainly clear with melanised veins and fibrous fringes on the hind wing edge. The anopheline wings have a patched, melanised fore-edge. Mainly the veins and fibrous fringes contribute to diffuse depolarised backscatter in the wing contribution since light is unlikely to undergo incoherent multiple scatter inside the nanometer thick membrane. Apparent melanization of thin transparent mosquito wing membranes cannot be expected to differ from the dorsal to ventral side.

\section{Materials and methods}

\subsection{Mosquito specimens}

This study include both sex of four species, see Figure1. All mosquitoes were bred at the Department of Plant Protection Biology, Swedish University of Agricultural Sciences in Alnarp, Sweden. Anopheles coluzzii (Suakoko strain, formerly referred to as Anopheles Gambiae molecular form M), An. arabiensis (Dongola strain), Aedes aegypti (Rockefeller strain) and Culex quinquefasciatus (Thai strain) were reared at $27 \pm 2^{\circ} \mathrm{C}, 70 \pm 2 \%$ relative humidity (RH) under a $12 \mathrm{~L}$ : $12 \mathrm{D}$ period, as previously described[64,65]. For all experiments, 6- to 14-days post-emergence sugar-fed adult female mosquitoes were used.

Anopheles coluzzii and An. arabiensis are among the key vectors of malaria in subSaharan Africa, and display a high anthropophilic and opportunistic host preference, respectively. While An. coluzzii endophilic and endophagic behaviour directly increases their interaction with humans, the exophilic and exophagic behaviour of An. arabiensis is a leading cause for residual malaria in sub-Saharan Africa. Similar to the two Anopheles species, the arboviral vector Culex quinquefasciatus is crepuscular, with host and resting preferences varying considerably depending on season and geographic location. Aedes aegypti, is a major 
vector for dengue, yellow fever and chikungunya, due to its mainly anthropophilic behaviour. Unlike the other species, Ae. aegypti is diurnal and mainly endophagic and endophilic.

Live specimens of mixed sexes from one species were captured using a suction tube from the mosquito cage, and then released inside the release chamber for individual detection (see below). Apart from the optical ports, the chamber was closed to keep the mosquitoes inside and to let them fly naturally. Sugar solution was placed below the FOV to attract the mosquitoes towards the probe volume and increase activity inside the chamber. Prior knowledge about the sexual difference between the WBF was used to distinguish them.

Measurements were carried out in $24-27^{\circ} \mathrm{C}$ ambient temperature, and humidity was kept at $60-70 \%$ inside the chamber to create a conducive environment for the mosquitoes to fly naturally.

\subsection{Instrumentation}

The scattering properties of insects were investigated with a multispectral, polarimetric setup, see Figure2. The transmitters are $3.2 \mathrm{~W}$ continuous wave $808 \mathrm{~nm}$ NIR and $1550 \mathrm{~nm}$ SWIR multimode diode lasers (both $1 \times 95 \mu \mathrm{m}$ aperture). The NIR and SWIR lasers were horizontally polarized and superimposed using a dichroic beam splitter. The light was expanded and collimated by a $ø 50, \mathrm{f} 300 \mathrm{~mm}$ lens. The collimated beams were transmitted across the room and terminated in a neoprene beam dump. Mosquitoes were released in a 1.1 $\mathrm{m}^{3}$ rectangular release chamber located around $1.5 \mathrm{~m}$ distance from the source. A rectified white LED light source was used to simulate crepuscular light conditions. To measure the light extinction of mosquitoes, a Brewster window was used to direct a fraction of the ballistic light to a photodiode. The light was focused onto the sensor with a $650 \mathrm{~mm}, \mathrm{f} 150$ mm lens. Neutral density filter prevented signal saturation.

Light was detected in backscatter mode by two Silicon ( $\mathrm{Si}$ ) and Indium Gallium Arsenide (InGaAs) sandwiched photodiodes (Photosensitive area: Si $2.4 \mathrm{~mm}$ x $2.4 \mathrm{~mm}$, 
InGaAs $\varnothing 1 \mathrm{~mm}$. Spectral response range: 0.32 to $1.7 \mu \mathrm{m})$. The background light was suppressed by a $\varnothing 50 \mathrm{~mm}$ RG780 long pass filter. The backscattered light was collected using a $ø 50 \mathrm{~mm}, \mathrm{f} 300 \mathrm{~mm}$ lens. The co- and de-polarized backscattered light was separated using a polarization beam splitter. The co-polarized light was transmitted to one of the sandwiched $\mathrm{Si} / \mathrm{InGaAs}$ detectors while the depolarized light was reflected to the second $\mathrm{Si} / \mathrm{InGaAs}$ detector. The detectors transimpedance amplifiers (TIA) were built using OPA404 operational amplifiers with $56 \mathrm{M} \Omega$ feedback resistors giving the sensors a $3-4 \mathrm{kHz}$ bandwidth. The signals were acquired by a USB data acquisition board using a sample rate of $20 \mathrm{kHz}$ (DAQ, National Instruments, NI USB6211, $250 \mathrm{kHz}$ shared).

The field of view of the detector (FOV) and laser beam overlapped in the centre of the release chamber. A high-speed CMOS camera mounted on top and a folding mirror tilted $50^{\circ}$ was setup at the release chamber to obtain $3 \mathrm{D}$ stereo vision. The camera was operated at 170 frames/s, it is equipped with a long pass filter. Video was triggered by insects lateral scattering of NIR laser light into the camera. The illuminated insect produces both a directly observed spot and a spot observed through the folding mirror. In each frame the centre-ofmass pixel positions are calculated for both direct observation and the folded observation. The two pixel coordinates are translated into 3D coordinate through hyperplanes. The coefficients of the hyperplanes are found by multivariate regression of calibration pictures of a scattering needle head at known positions, for details see[66].

\subsection{Signal processing}

The signals and data processing flow are outlined in Table.1. A number of norms such as the minimum-, maximum-, median-norm from the class of descriptive statistics are employed. Also variance will later be reported as corresponding interquartile range. Descriptive statistics is robust and insensitive to outliers when certainty of processing steps are sub-ideal.

This article is protected by copyright. All rights reserved. 
A total number of 5 channels, $I_{t, b, n}$, are recoded at $20 \mathrm{kHz}$. Here, $t$ is time, $b$ is band and $n$ is observation number belonging to groups of species and sex. The recorded mosquito signals are calibrated into cross sections, $\sigma_{t, b, n}$, by dropping $ø 6.35 \mathrm{~mm}$ diffuse white spheres through the probe volume. All channels were calibrated assuming that the spheres have Lambertian reflectance of $100 \%$ and that they are $100 \%$ opaque. The procedure is described in previous reports[26,67].

To identify the WBF, $f_{0}$, a combination of several frequency analysis methods have been implemented to improve accuracy of WBF estimation. We have used autocorrelation, cepstrum, harmonic product spectrum[68-70], which are commonly used in musical analysis and speech recognition. A method based on change of slope was also used and this method finds two indices in a vector when slope changes from negative to positive and find the first peak in the spectrum, which is considered as $f_{0}$. The $f_{0}$ value selected by most of the frequency analysis methods was chosen as the final WBF of the mosquito species. The final WBF was also manually verified to evaluate the performance of those methods and the consistency ratio was $85-90 \%$.

The contribution of the insect body, $\sigma_{b o d y, t, b, n}$, to the total cross section is estimated by applying a sliding minimum norm to the signal with a width equal to the wing beat period, as previously described[32,35]. The cross section where the mosquitoes are fully within the probe volume is estimated from the maximum norm of the observed envelope.

Several unit-less ratios are introduced. This includes $D o L P_{b, n}$ for the body contribution for both NIR and SWIR wavelengths. A spectral ratio, $S_{n}$, between depolarized SWIR and NIR backscatter is introduced for both body and wing contribution. This ratio increases with melanisation and decreases with liquid the water absorption imprint. Finally, a ratio between backscattered and extinguished light is used to estimate the reflectance, $R_{t, b, n}$, for all bands. 
The specular glossiness, $\sigma_{s p e c, b, n}$, is calculated from the deviation from diffuse cross sections. The deviation is calculated from depolarized cross section times a scalar. The scalar is the inverse $D o L P$ from the body.

\section{Measurements and results}

\subsection{Dualband backscattered signal}

The scattered light from mosquitoes flying into the probe volume is observed as an oscillatory signal component due to the wing beats, and a non-oscillatory signal (DC) component from the body. Figure3a. show a typical example of the signals detected when a mosquito flies through the probe volume. The backscattered signal from a $q$ An. coluzzii is shown in co- and de-polarized mode in both spectral bands, together with the extinguished signal. The extinction detector only has the NIR band. The co-polarized signal contains both specular and single scattered light from the surface as well as from diffuse multiple scattered light from the tissue. The de-polarized signal contains only the diffuse multiple scattered light. Polarization is used to determine whether the light is reflected specularly from the surface or multiple scattered from inside the tissue, see Figure $3 \boldsymbol{b}$. The non-oscillatory component, $\sigma_{b o d y}$, and oscillatory component, $\sigma_{\text {wing }}$, is used to derive whether the signal is from the body or wing respectively. Glossy wings or body parts give rise to a strong specular reflections and polarization is preserved. Specular reflections are thus extracted from the copolarized signal by subtracting the diffuse backscatter light. The amplitude of the specular reflection, $\sigma_{s p e c, b, n}$, is used to assess wing glossiness. 


\subsection{Aspects of orientation independent parameters}

Although coarse insect classifications can be based on the absolute cross sections[12,33], a particular challenge for classification of free flying insects is the fact that both scatter cross sections and the harmonic content changes with the lateral aspect or flight heading $[34,49,55]$. We investigated whether our unit-less parameters, DoLP and $S$, were dependent on the aspect of observation. We used the time-dependent OCS, $\sigma_{t}$, to calculate the $D o L P_{t}$ and $S_{t}$ during a observation. We also used the 3D stereo vision to capture the flight trajectory simultaneously. The cross sections and trajectory is shown in Figure4. As can be seen in the figure, both the OCS and the heading varies considerably during the recording. The cross sections varies both because of varying aspect and diminishes at the edges of the beam. The duration of the trajectory data is slightly smaller than the OCS signal since the stereo camera FoV is smaller than the probe volume of the multiband $\mathrm{kHz}$ instrument. The particular observation shown in

Figure4 is a $\odot$ C. quinquefasciatus and was chosen for display because of its long duration and curved trajectory. In Figure5 we present three aspect-independent parameters, namely $D o L P_{N I R}, D o L P_{S W I R}$ and spectral body ratio $S_{b o d y}$ during the same observation presented in Figure4, we will later present median values for these parameters for all the observations.

Unlike the absolute cross sections, $\sigma_{t}$, which varies from 0 to $3 \mathrm{~mm}^{2}$, the variance of the body DoLP and spectral ratio in Figure $5 \boldsymbol{b}$ of this mosquito is only around 5\%. This could be true with other insect species as well if the insect body is equally glossy and melanized on all sides. However, since melanization and glossiness can vary between different parts of insect bodies the aspect of observation may still have an impact. Still, these parameters are to a large extent invariant to the aspect of observation compared to absolute cross sections as can be seen in Figure5. This is useful to distinguish different mosquito species regardless of the orientation of the insect at the time of detection. 


\subsection{Identification of mosquito species and sex}

WBF can be used to distinguish male and female mosquitoes, as shown in Figure6 with $\widehat{\sigma}$ and $q$ C. quinquefasciatus. We have used median and inter-quartile-range (IQR) from descriptive statistics because they are robust and insensitive to outliers. The median and IQR of the distribution shows that there is no WBF overlap between $\delta^{\lambda}$ and $q$ C. quinquefasciatus. This is also true for the other mosquito species analysed in this work. Our WBF values are in accordance with reported values in previous studies $[18,71]$. WBFs are sufficient to distinguish $\widehat{\partial}$ Ae. aegypti from C. quinquefasciatus, and An. arabiensis, but $\widehat{\partial}$ An. coluzzii and An. arabiensis have similar WBF, which makes it difficult to distinguish these two species, see Figure7b. The WBF distributions of $q$ An. coluzzii, An. arabiensis and C. quinquefasciatus overlap as can be seen in Figure7a.

Although An. coluzzii and An. arabiensis cannot be distinguished by $f_{0}$ or $D o L P$, the spectral ratio, $S$, is useful to separate these two species, as shown in Figure8. The $S$ can be affected by both water and melanin absorption. A high spectral ratio indicates a high melanization and/or a low water absorption, whereas a low spectral ratio indicates the opposite. Using the $S, q$ and $\hat{\sigma} A n$. coluzzii can largely be distinguished from $q$ and $\hat{\sigma} A n$. arabiensis.

Both wing and body spectral ratios of $q$ and $\widehat{\partial} A n$. coluzzii are more melanized than $A n$. arabiensis. This indicates that melanization can be used to distinguish these two species. The body spectral ratio has larger variation compared with wing spectral ratio for both species. This could be due to the variation of water absorption[44] dip magnitude, which depends on body tissue scatter coefficient[42].

NIR and SWIR wing glossiness, $\sigma_{\text {spec }}$, can also be used to distinguish the two malaria mosquitoes (An. coluzzii and An. arabiensis), see Figure9. The NIR wing glossiness of An. coluzzii is lower than that of An. arabiensis for both $\hat{\delta}$ and $q$ mosquitoes. This could be 
explained by the NIR band is sensitive to melanization, which lowers the amplitude of NIR specular reflection of An. coluzzii. However, the increase in the median specular reflex increases in the SWIR, rather implies that the wing membrane differ in thickness. The wing membrane is around $400 \mathrm{~nm}$ thick and the specular reflex could arise from both front and back of the surface. As a result, melanisation could increase refractive index of the surface and attenuate contributions from the chitin-air interface.

\subsection{Table values}

Median and IQR were calculated to create table values of $f_{0}$, cross sections, $\sigma_{b}$, body, $D o L P_{b}$, spectral ratios, $S$, wing glossiness $\sigma_{s p e c, b}$ as well as NIR and SWIR reflectance, $R$, see Table.2. The difference between the median $f_{0}$ of $Q_{+}$An. coluzzii and An. arabiensis is only $25 \mathrm{~Hz}$ and the IQR values are $53 \mathrm{~Hz}$ and $92 \mathrm{~Hz}$, respectively, indicating that the frequency distributions of the two species overlap. Also the $q$ C. quinquefasciatus overlaps in frequency with the Anophelines.

The median SWIR reflectance, $R_{S W I R}$, for both sex of An. coluzzii is surprisingly double that of An. arabiensis. This could be due to water absorption of the $1550 \mathrm{~nm}$ light. One particular challenge of contrasting this set of species is the close resemblance of $q C$. quinquefasciatus with $\bigcirc$ An. coluzzii. Most parameters differ more between the Anophelines than between $q$ An. coluzzii and $q$ C. quinquefasciatus. However, the extinction cross section, $\sigma_{\text {ext. }}$, differ somewhat. The largest $\sigma_{\text {ext. }}$ is displayed by An. arabiensis for both sex, but it is more pronounces with the females. Extinction OCS of An. arabiensis is about $60 \%$ higher than that of An. coluzzii, indicating a larger body. Since both $\mathrm{R}$ and $\sigma_{\text {ext. }}$ are based on retrieval of extinction more emphasis should be put on retrieving stable extinction coefficient in entomological lidar work. 
The median NIR DoLP shows that C. quinquefasciatus and Ae. aegypti have the lowest and highest $D o L P$, respectively, compared with the other species investigated in this work. This could be because $C$. quinquefasciatus has a relatively hairy body as compared to Ae. aegypti or because of the strongly melanised Aedes. The DoLP of the males is consequently higher than for the conspecific females. We presume that male depolarisation is attributed the fluffy antennas. Overall, the $D o L P$ all the investigated mosquito classes and this may be more useful for other insect classification problems such as moths and bees.

The spectral body ratio, $S_{\text {body }}$, display a large overlap with largest discrepancy between the two Anopheline species. The spectral wing ratio, $S_{\text {wing }}$, display better contrast for the Anopheline species but the $q$ An. coluzzii and $q$ C. quinquefasciatus largely overlap. Detailed scatter plot of spectral ratios can be found in supplementary material

\section{SI_CulexVsAnohelines.}

The 10 dimensional data in Table.2. is challenging to overview. We check the set of parameters for redundancy by analysing parameter covariance, see supplementary material, SI_ParamCov. The data was centered, normalized by variance and compensated for group sizes. We found only minor covariance. To get an idea of classification accuracy the data was fed to a Naive Bayes Classifier (default settings, Matlab by MathWorks). The resulting confusion matrix can be found in supplementary material, SI_Confusion. The average accuracy was some $81 \%$, with $q$ Ae. aegypti being the most difficult (61\%) and $\lesssim$ Ae. aegypti being the easiest to identify (94\%). Such rating tells little about classification accuracy for in situ monitoring where other mosquito species may appear. On the other hand previous studies have demonstrated increased specificity when including harmonic content $[18,72]$ and refinement of classification algorithm could yield higher accuracy. 


\section{Discussion and conclusion}

We have implemented a $\mathrm{kHz}$ multispectral polarimetric system to remotely distinguish species and sexes of disease vector mosquitoes in flight. Based on the spectral- and polarization properties of the mosquitoes, parameters such as $S, D o L P$ and wing glossiness, $\sigma_{s p e c, b}$ in the NIR and SWIR bands can be assessed. In addition, due to the $\mathrm{kHz}$ sampling the wing-beat frequencies of mosquitoes can be determined. These are the two main findings of this work:

First main finding: the spectral ratio, $S$, of body and wings and the body $D o L P_{b}$, in both NIR and SWIR bands, were found to be largely unaffected by the aspect of observation. These ratios were found relatively stable while the cross sections, $\sigma$, showed large fluctuations due to changes in flight heading. As long as a specular spike appear, glossiness, $\sigma_{s p e c, b}$, is also aspect insensitive because specular reflection from glossy wing can only be measured when the surface normal of the wing coincide with the optical axis.

Second main finding: the $S$ of mosquito wings and bodies, as well as the NIR and SWIR wing glossiness are shown to allow for the distinguishing of the two similar mosquito species (An. coluzzii and An. arabiensis), which have similar $f_{0}$. The body and wing spectral ratio clearly shows that An. coluzzii is more melanised compared to An. arabiensis. The NIR wing glossiness of An. coluzzii is lower than An. arabiensis, which indicates that melanin and maybe even wing membrane thickness can be used to differentiate the two malaria vectors through body $S$ or relative wing glossiness, $\sigma_{s p e c, b}$ in the two bands.

Based on this work, clues are provided of the potential of optically differentiating species and sexes of mosquitoes. Several benefits for dual spectral band and polarimetric detection are revised, forming a basis for band selection and lidar implementations. We conclude that multiple bands can significantly improve the specificity of entomological lidar 
and foresee numerous applications for in situ surveillance and improved understanding and preventive measures to address health impact caused by insects.

\section{Acknowledgements}

We thank Elsa Quillery and Elin Isberg at the Chemical Ecology Unit at the Department of Plant Protection Biology, Swedish Agricultural University in Alnarp, for providing all mosquito species for our measurements. Klas Rydhmer, Alfred Strand, Mikkel Hedegaard Jensen for helping with experiment and data analysis. The study was financially supported by FaunaPhotonics and The Innovation Foundation, Denmark, the Swedish Research Council, the Physiographical Society in Lund, a Linnaeus grant to the Lund Laser Centre, and a direct grant from the vice chancellor of Lund University.

\section{References}

[1] W. H. Organization. (2017). Vector Control. Available: http://www.who.int/vectorcontrol/en/

[2] D. J. Gubler, Emerging infectious diseases, 4, 442,(1998).

[3] C. J. L. Murray, L. C. Rosenfeld, S. S. Lim, K. G. Andrews, K. J. Foreman, D. Haring, N. Fullman, M. Naghavi, R. Lozano, and A. D. Lopez, The Lancet, 379, 413-431,(2012).

[4] W. H. Organization, World malaria report 2016: World Health Organization, 2016).

[5] V. Corbel, M. Akogbeto, G. B. Damien, A. Djenontin, F. Chandre, C. Rogier, N. Moiroux, J. Chabi, G. G. Padonou, and M.-C. Henry, The Lancet infectious diseases, 12, 617-626,(2012).

[6] M. Yohannes and E. Boelee, Medical and veterinary entomology, 26, 103-105,(2012).

[7] M. L. Gatton, N. Chitnis, T. Churcher, M. J. Donnelly, A. C. Ghani, H. C. J. Godfray, F. Gould, I. Hastings, J. Marshall, and H. Ranson, Evolution, 67, 1218-1230,(2013).

[8] A. Dao, A. S. Yaro, M. Diallo, S. Timbine, D. L. Huestis, Y. Kassogue, A. I. Traore, Z. L. Sanogo, D. Samake, and T. Lehmann, Nature, 516, 387-390,(2014).

[9] H. M. Ferguson, A. Dornhaus, A. Beeche, C. Borgemeister, M. Gottlieb, M. S. Mulla, J. E. Gimnig, D. Fish, and G. F. Killeen, PLoS Med, 7, e1000303,(2010).

[10] G. Benelli, Asian Pacific Journal of Tropical Biomedicine, 6, 468-471,(2016).

[11] C. Kirkeby, M. Wellenreuther, and M. Brydegaard, Scientific Reports, 6, 29083,(2016).

[12] E. Malmqvist, S. Jansson, S. Zhu, W. Li, K. Svanberg, S. Svanberg, J. Rydell, Z. Song, J. Bood, M. Brydegaard, and S. Åkesson, Interface, 2018 submitted).

[13] Z. Guan, M. Brydegaard, P. Lundin, M. Wellenreuther, A. Runemark, E. Svensson, and S. Svanberg, Appl. Opt. , 49, 1-11,(2010).

[14] E. W. Kaindoa and H. S. Ngowo, 2, 88,(2017).

[15] S. P. Sawadogo, A. Niang, E. Bilgo, A. Millogo, H. Maïga, R. K. Dabire, F. Tripet, and A. Diabaté, PLOS ONE, 12, e0173273,(2017).

[16] J. B. Silver, Mosquito ecology: field sampling methods: Springer Science \& Business Media, 2007). 
[17] Y.-N. Liu, Y.-J. Liu, Y.-C. Chen, H.-Y. Ma, and H.-Y. Lee, Scientific reports, 7, 40074,(2017).

[18] Y. Chen, A. Why, G. Batista, A. Mafra-Neto, and E. Keogh, Journal of insect behavior, 27, 657-677,(2014).

[19] I. Potamitis, I. Rigakis, and K. Fysarakis, PLoS ONE, 10, e0140474,(2015).

[20] L. Mboera, B. Knols, M. Braks, and W. Takken, Medical and veterinary entomology, 14, 257-263,(2000).

[21] C. Costantini, G. Gibson, N. F. Sagnon, A. D. Torre, J. Brady, and M. Coluzzi, Medical and veterinary entomology, 10, 220-227,(1996).

[22] D. V. Maliti, N. J. Govella, G. F. Killeen, N. Mirzai, P. C. D. Johnson, K. Kreppel, and H. M. Ferguson, Malaria Journal, 14, 502,(2015).

[23] N. J. Govella, P. P. Chaki, Y. Geissbuhler, K. Kannady, F. Okumu, J. D. Charlwood, R. A. Anderson, and G. F. Killeen, Malaria Journal, 8, 157-157,(2009).

[24] O. Kenea, M. Balkew, H. Tekie, T. Gebre-Michael, W. Deressa, E. Loha, B. Lindtjørn, and H. J. Overgaard, Malaria Journal, 16, 30,(2017).

[25] J. R. Hagler and C. G. Jackson, Annual review of entomology, 46, 511-543,(2001).

[26] M. Brydegaard, A. Merdasa, A. Gebru, H. Jayaweera, and S. Svanberg, Applied Spectroscopy, 70, 372-385,(2016).

[27] K. A. Hartfield, K. I. Landau, and W. J. D. v. Leeuwen, Remote Sensing, 3, 23642383,(2011).

[28] T. L. Millette, B. A. Argow, E. Marcano, C. Hayward, C. S. Hopkinson, and V. Valentine, J. Coastal Research, 265, 809-816,(2010).

[29] M. Brydegaard, E. Malmqvist, S. Jansson, J. Larsson, S. Török, and G. Zhao, SPIE Lidar Remote Sensing for Environmental Monitoring, 10406, 2017).

[30] K. S. Repasky, J. A. Shaw, R. Scheppele, C. Melton, J. L. Carsten, and L. H. Spangler, Appl. Opt., 45, 1839-1843,(2006).

[31] M. Brydegaard, A. Gebru, and S. Svanberg, Prog. Electromagn. Res., 147, 141-151,(2014).

[32] E. Malmqvist, S. Jansson, S. Torok, and M. Brydegaard, Selected Topics in Quantum Electronics, IEEE Journal of, 22, 327-334,(2016).

[33] M. Brydegaard, A. Gebru, C. Kirkeby, S. Åkesson, and H. Smith, "Daily evolution of the insect biomass spectrum in an agricultural landscape accessed with lidar," in ILRC 27, New York, USA, (Year).

[34] M. Brydegaard, PLoS One, 10, e0135231,(2015).

[35] A. Gebru, M. Brydegaard, E. Rohwer, and P. Neethling, SPIE, Journal of Applied Remote Sensing, 16611P, 2016).

[36] M. Brydegaard, J. Larsson, S. Török, E. Malmqvist, G. Zhao, S. Jansson, M. Andersson, S. Svanberg, S. Åkesson, F. Laurell, and J. Bood, ILRC28, 2017).

[37] S. Zhu, E. Malmqvist, Y. Li, S. Jansson, W. Li, Z. Duan, W. Fu, K. Svanberg, J. Bood, H. Feng, S. Åkesson, Z. W. Song, B. X. Zhang, G. Zhao, D. S. Li, M. Brydegaard, and S. Svanberg, ILRC28, 2017).

[38] M. Brydegaard, "Advantages of shortwave infrared LIDAR entomology," in Imaging and Applied Optics 2014, Seattle, Washington, (Year), p. LW2D.6.

[39] L. Mei and P. Guan, Optics Letters, 42, 3562-3565,(2017).

[40] J. A. Shaw, N. L. Seldomridge, D. L. Dunkle, P. W. Nugent, and L. H. Spangler, Opt. Expr., 13, 5853-5863,(2005).

[41] S. L. Jacques and B. W. Pogue, J. Biomed. Opt., 13, 041302,(2008).

[42] S. L. Jacques, Physics in medicine and biology, 58, R37,(2013).

[43] M. Burresi, L. Cortese, L. Pattelli, M. Kolle, P. Vukusic, D. S. Wiersma, U. Steiner, and S. Vignolini, Scientific reports, 4, 2014).

[44] G. M. Hale and M. R. Querry, Appl. Opt., 12, 555-563,(1973).

[45] H. Pratt and C. Stojanovich, US Department of health, education, and welfare public. Health service. US Government printing office Washington, 191,(1969).

[46] S. L. Jacques, "Monte Carlo modeling of light transport in tissue (steady state and time of flight)," in Optical-Thermal response of laser-irradiated tissue, ed: Springer, 2010), pp. 109144. 
[47] S. L. Jacques, "Polarized Light Imaging of Biological Tissues," in Handbook of biomedical optics, D. A. Boas, C. Pitris, and N. Ramanujam, Eds., ed: CRC press, 2016), pp. 649-669.

[48] M. F. Land, Progress in Biophysics and Molecular Biology, 24, 75-106,(1972).

[49] I. Potamitis and I. Rigakis, Applied Acoustics, 109, 54-60,(2016).

[50] A. Moore and R. H. Miller, Ann. Entomol. Soc. Am., 95, 1-8,(2002).

[51] M. J. Lehane, The biology of blood-sucking in insects: Cambridge University Press, 2005).

[52] M. A. B. Deakin, Journal of Insect Science, 10, 96-96,(2010).

[53] G. J. Berman and Z. J. Wang, Journal of Fluid Mechanics, 582, 153-168,(2007).

[54] R. J. Bomphrey, T. Nakata, P. Henningsson, and H.-T. Lin, Phil. Trans. R. Soc. B, 371, 20150389,(2016).

[55] V. Drake, International Journal of Remote Sensing, 37, 3811-3835,(2016).

[56] D. F. Silva, V. M. Souza, D. P. Ellis, E. J. Keogh, and G. E. Batista, Journal of Intelligent \& Robotic Systems, 80, 313-330,(2015).

[57] T. Ganchev, Computational Bioacoustics: Biodiversity Monitoring and Assessment: Walter de Gruyter GmbH \& Co KG, 2017).

[58] D. G. Stavenga, Materials Today: Proceedings, 1, 109-121,(2014).

[59] N. Katayama, J. K. Abbott, J. Kjærandsen, Y. Takahashi, and E. I. Svensson, Proceedings of the National Academy of Sciences, 111, 15144-15148,(2014).

[60] E. Shevtsova, C. Hansson, D. H. Janzen, and J. Kjaerandsen, PNAS, 108, 668-73,(2011).

[61] V. S. Mayagaya, K. Michel, M. Q. Benedict, G. F. Killeen, R. A. Wirtz, H. M. Ferguson, and F. E. Dowell, Am. J. Trop. Med. Hyg., 81, 622-30,(2009).

[62] K. H. Peiris, B. S. Drolet, L. W. Cohnstaedt, and F. E. Dowell, American Journal of Agricultural Science and Technology, 2, 49-61,(2014).

[63] M. Sikulu, G. F. Killeen, L. E. Hugo, P. A. Ryan, K. M. Dowell, R. A. Wirtz, S. J. Moore, and F. E. Dowell, Parasit. Vectors, 3, 49,(2010).

[64] S. Majeed, S. R. Hill, G. Birgersson, and R. Ignell, Royal Society open science, 3, 160467,(2016).

[65] B. Wondwosen, G. Birgersson, E. Seyoum, H. Tekie, B. Torto, U. Fillinger, S. R. Hill, and R. Ignell, Scientific reports, 6, 2016).

[66] S. Török, "Kilohertz electro-optics for remote sensing of insect dispersal," Master Msc thesis, Department of Physics, Lund University, 2013.

[67] A. Gebru, E. Rohwer, P. Neethling, and M. Brydegaard, J. Appl. Remote Sens., 8, 083503083503,(2014).

[68] A. V. Oppenheim and R. W. Schafer, IEEE signal processing Magazine, 21, 95-106,(2004).

[69] A. De Cheveigné and H. Kawahara, The Journal of the Acoustical Society of America, 111, 1917-1930,(2002).

[70] M. R. Schroeder, The Journal of the Acoustical Society of America, 43, 829-834,(1968).

[71] I. Potamitis, Ecological Informatics, 21, 40-49,(2014).

[72] G. E. Batista, E. J. Keogh, A. Mafra-Neto, and E. Rowton, "SIGKDD demo: sensors and software to allow computational entomology, an emerging application of data mining," presented at the Proc. 17th ACM SIGKDD internat. conf. knowledge discovery and data mining, San Diego, California, USA, (2011). 


\section{Figure 2}

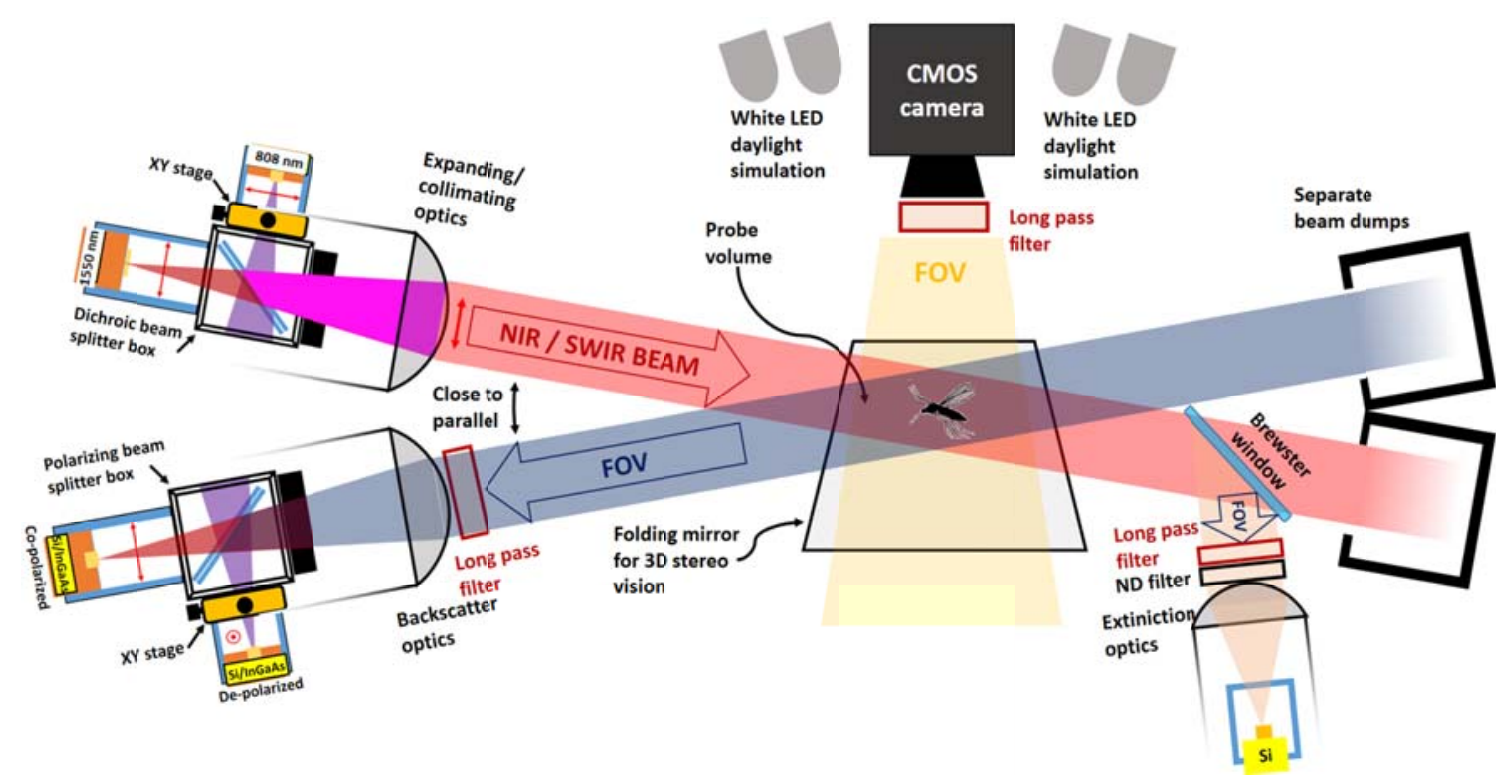

Figure 2: Multispectral polarimetric setup used to characterise the scattering properties of insects. Linearly polarized $808 \mathrm{~nm}$ and $1550 \mathrm{~nm}$ laser diodes were overlapped and transmitted across the room. Silicon (Si) and Indium Gallium Arsenide (InGaAs) sandwiched detectors were used to measure the backscattered co-polarized and depolarized light. A silicone photodiode (Si PD) measures light extinguished by insects. A Si-CMOS camera together with a folding mirror was used to map the flight trajectory of insects in $3 D$ through stereo vision. 


\section{Table 1}

\begin{tabular}{|c|c|c|c|}
\hline Variable & Given by & Unit & Explanation \\
\hline$I_{t b, n}$ & $\begin{array}{l}\text { Photodiodes signals after } \\
\text { transimpedance amplifiers. }\end{array}$ & $V$ & $\begin{array}{l}\text { Recorded light intensity as function of time, } \\
\text { band and observation number. }\end{array}$ \\
\hline$t$ & $l / f_{s}$ & $\mu s$ & $\begin{array}{l}\text { Time samples given by sample rate, } f_{s}=20 \mathrm{kHz} \text {. } \\
-3 \mathrm{~dB} \text { bandwidth @ } \sim 4 \mathrm{kHz} \text {. }\end{array}$ \\
\hline $\bar{b}$ & $\begin{array}{l}b \in 1 . .5 \\
\left\{\begin{array}{c}808 n m_{\|}, 808 n m_{\vdash} \\
1550 m_{\|}, 1550 n m_{\vdash} \\
808 n m_{\text {ext. }}\end{array}\right\}\end{array}$ & $\#$ & $\begin{array}{l}\text { Instrument bands: } \\
808 \mathrm{~nm}, \text { near infrared (NIR) } \\
1550 \mathrm{~nm} \text {, short wave infrared (SWIR) } \\
\text { // co-polarized backscatter } \\
\text { F de-polarized backscatter } \\
\text { ext. extinction band }\end{array}$ \\
\hline$n$ & $\begin{array}{l}n \in 1 . N \\
\left\{\begin{array}{c}\text { Sex } \\
\text { Species } \\
\text { Sphere }\end{array}\right\}\end{array}$ & $\#$ & $\begin{array}{l}\text { Observation number belonging to groups of } \\
\text { four species of each sex or reference calibration } \\
\text { spheres. }\end{array}$ \\
\hline$\sigma_{t b, n}$ & $\pi r^{2} \Delta I_{\Delta t, b, n} /\left\|\Delta I_{\Delta t, b, n \in s p h e r e}\right\|_{\infty}$ & $m m^{2}$ & $\begin{array}{l}\text { Calibrated time dependent optical cross-section } \\
\text { for band } b \text { and observation } n \text {. The radius, } r \text {, is } \\
\text { of } a \text { white Lambertian Teflon sphere. }\end{array}$ \\
\hline$f 0, n$ & $\begin{array}{l}\text { Various pitch detection methods } \\
\text { followed by manual inspection. }\end{array}$ & $\mathrm{Hz}$ & $\begin{array}{l}\text { Fundamental frequency or wing beat frequency } \\
\text { for observation, } n \text {. }\end{array}$ \\
\hline$\sigma_{b a d v: t, n}$ & $\left|\sigma_{t-\frac{2}{f_{0, n}}, \ldots t+\frac{2}{f_{0, n}}, b, n}\right|$ & $m m^{2}$ & $\begin{array}{l}\text { Time dependent body contribution from } \\
\text { sliding minimum norm within one wing beat } \\
\text { period for each band, } b \text {, and observation, } n \text {. }\end{array}$ \\
\hline$\left\|\sigma_{b o d t: b, n}\right\|$ & $\left\|\sigma_{b o d y, t, b, n}\right\|_{\infty}$ & $m m^{2}$ & $\begin{array}{l}\text { Full body contribution from maximum norm of } \\
\text { body contribution for each band, } b \text {, and } \\
\text { observation, } n \text {. }\end{array}$ \\
\hline$\sigma_{\text {wing } b, n}$ & $\sigma_{t, b, n}-\sigma_{b o d y, t, b, n}$ & $\mathrm{~mm}^{2}$ & Time dependent wing contribution. \\
\hline$\left\|\sigma_{\text {rivg } b, n}\right\|$ & $\left\|\sigma_{\text {wing,b,n }}\right\|_{\infty}$ & $m m^{2}$ & $\begin{array}{l}\text { Full wing contributions from maximum norm of } \\
\text { oscillatory part. }\end{array}$ \\
\hline$D o L P_{b, n}$ & $\frac{\left\|\sigma_{\text {body } 1 b, n}\right\|}{\left\|\sigma_{\text {body } \mid b, n}\right\|+\left\|\sigma_{\text {bod } y \| b, n}\right\|}$ & $\%$ & $\begin{array}{l}\text { Degree of Linear Polarisation for the body, } \\
\text { where } b \in\{-N I R,+S W I R\} \text {. }\end{array}$ \\
\hline$\sigma_{0, t, b, n}$ & $\frac{\operatorname{DoLP}_{b, n} \sigma_{t, k b, n}}{1-D o L P_{b, n}}$ & $m m^{2}$ & $\begin{array}{l}\text { Diffuse or incoherent scattering estimated from } \\
\text { the depolarized back scatter and DoLP from the } \\
\text { bocky. }\end{array}$ \\
\hline$\sigma_{\text {spec,b,n }}$ & $\left\|\sigma_{t, \| b, n}-\sigma_{d i f f, t, b, n}\right\|_{\infty}$ & $m m^{2}$ & Specular spike contribution from wings \\
\hline Sboat, n & $\left\|\frac{\sigma_{b o d y, t,+S W I R, n}}{\sigma_{b \circ d y, t,+S W I R, n}+\sigma_{b o d y, t,+N I R, n}}\right\|_{\text {med }}$ & $\%$ & $\begin{array}{l}\text { Spectral ratio of depolarized body light. } \\
\text { Median value during whole observation. }\end{array}$ \\
\hline Swing & 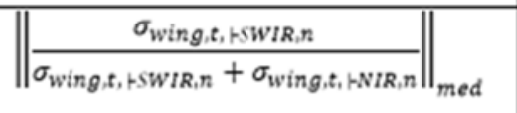 & $\%$ & $\begin{array}{l}\text { Spectral ratio of depolarized wing light. } \\
\text { Median value during whole observation. }\end{array}$ \\
\hline$R_{b, n}$ & $\frac{\left\|\sigma_{\text {body,b,n }}\right\|}{\left\|\sigma_{\text {body,ext,n }}\right\|}$ & $\%$ & $\begin{array}{l}\text { Body reflectance in band } b \text { for observation } n \\
b \in\{\text { Backscatter modes }\} \text {. }\end{array}$ \\
\hline
\end{tabular}

Table 1: Definition of variables and parameters presented in this report. 


\section{Figure 3}
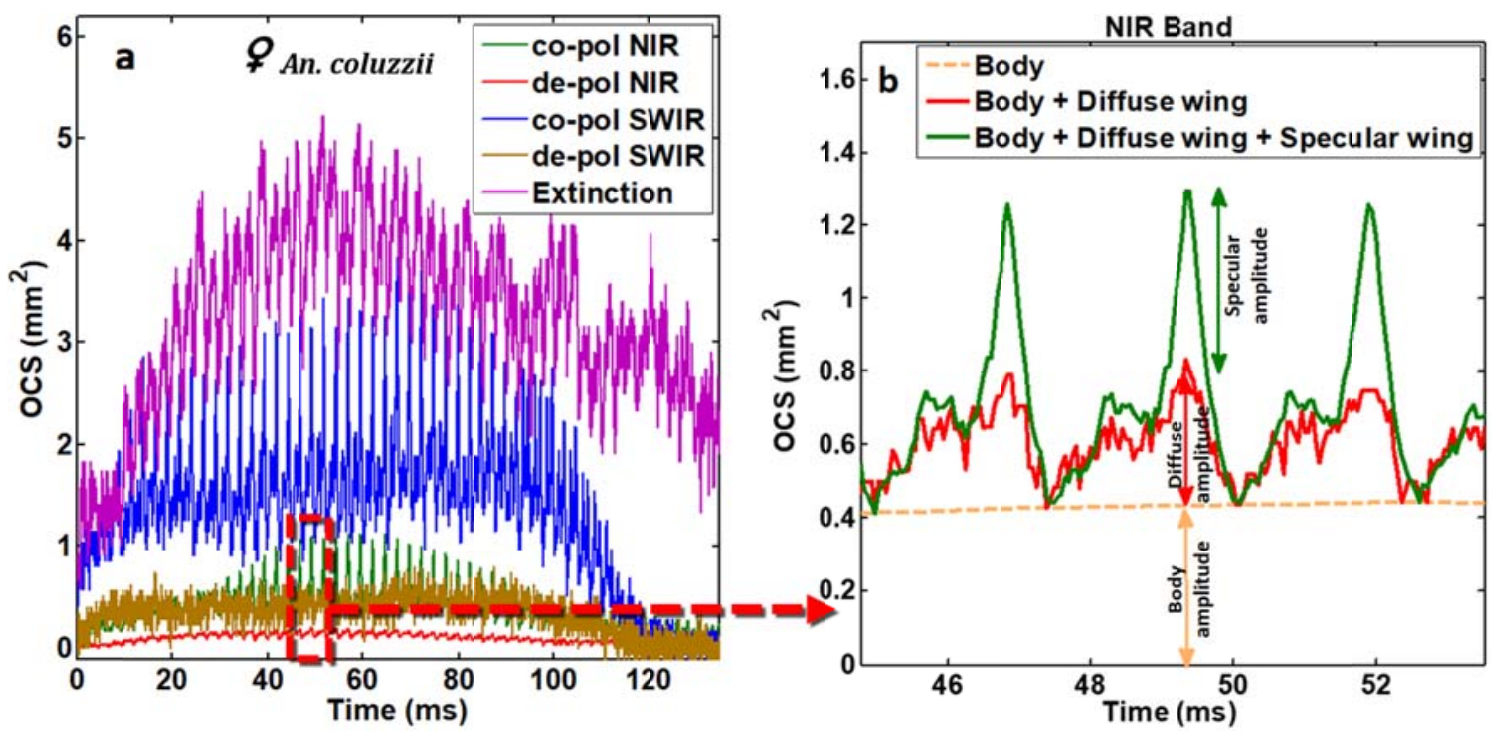

Figure 3: Multispectral polarimetric entomological signal acquired with the system described in Figure2.

Here, 3a: Backscattered and extinguished signal from a female An. coluzzii. The co-polarized (co-pol) and depolarized (de-pol) signals in the two bands (NIR and SWIR) are in backscattered mode. NIR extinction signal is used to assess the insect size through the amount of blocked light (extinguished signal). $3 \boldsymbol{b}$ : Close-up of the boxed waveform in 3a: illustrating different obtained parameters such as the contribution of the specular wing, diffuse wing and insect body to the total OCS in the NIR band. 


\section{Figure 4}
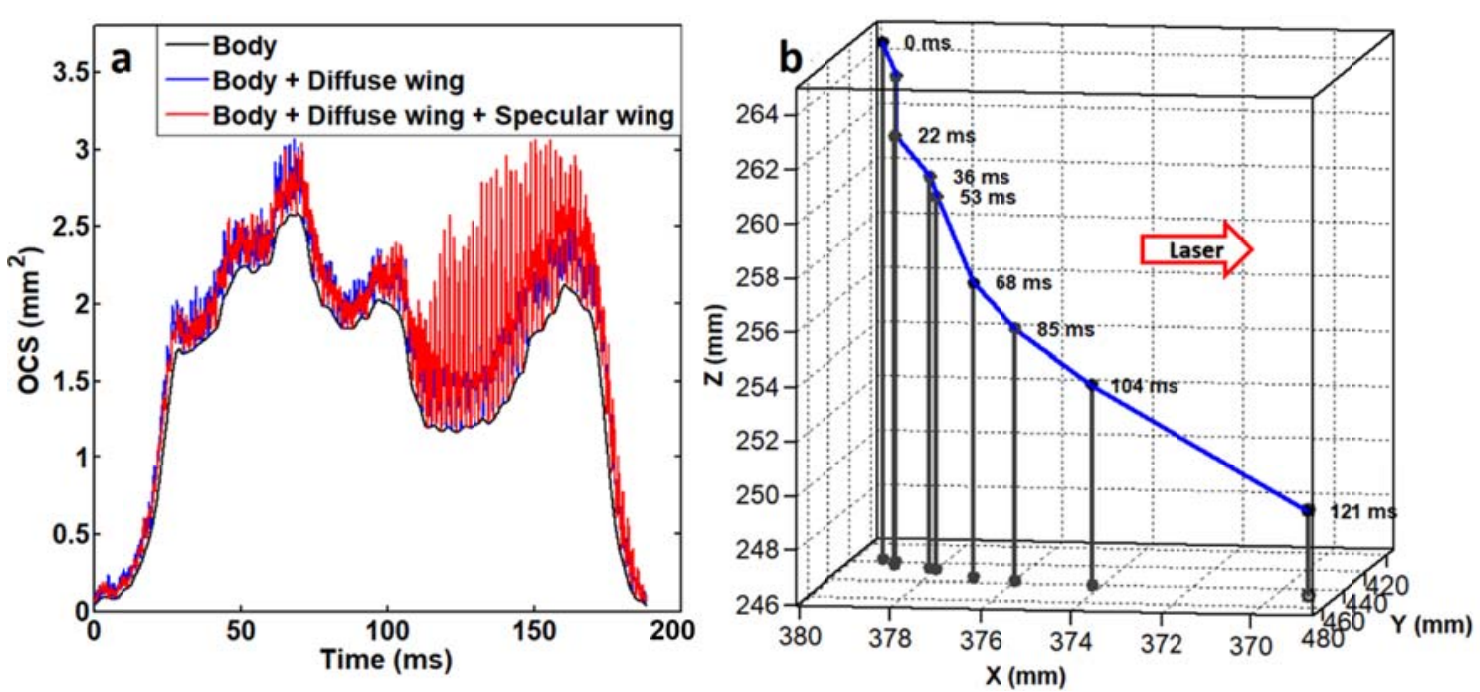

Figure 4: A female C. quinquefasciatus detected by the high-speed camera and NIR photodiodes. 4a: Contribution of body, diffuse wing and specular wing signal to the total OCS of the mosquito and its variation in time. The OCS changes considerably throughout the course of the mosquito flying through the probe volume. 4b: A 3D flight trajectory acquired with the high-speed camera shows that the mosquito changes its course, which supports $4 a$. 


\section{Figure 5}

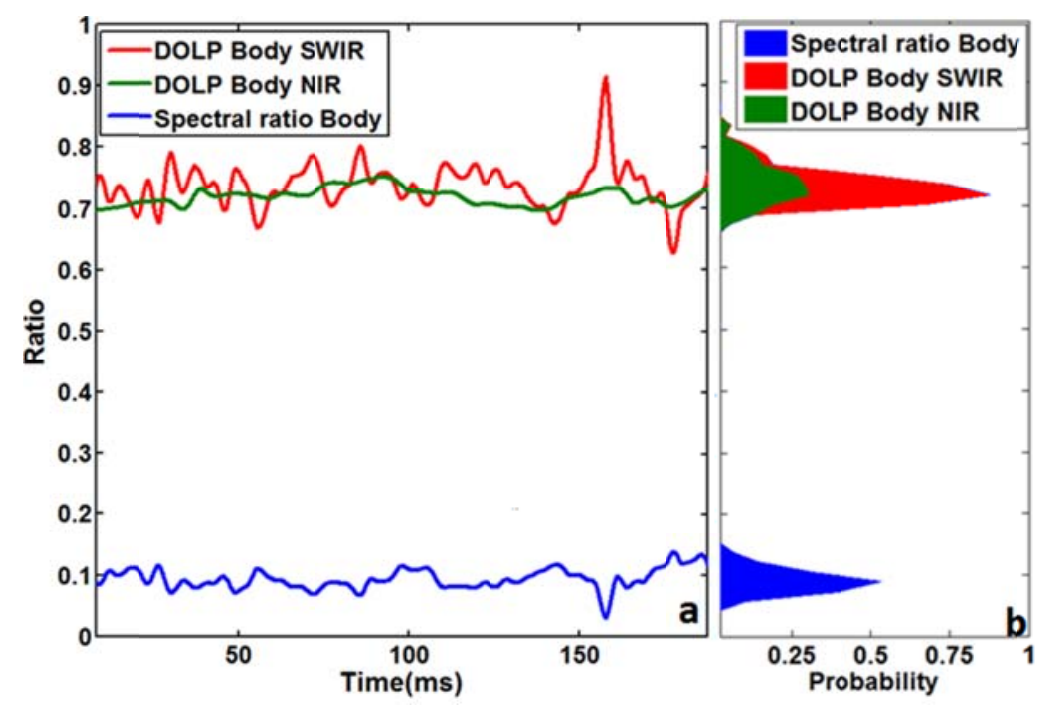

Figure 5: Ratio of different parameters mainly unaffected by the aspect of observation. 5a: The same mosquito as in Figure4. is presented here. DoLP of backscattered light from the body of this mosquito in the NIR-and SWIR bands, and the spectral ratio, $S$, of the body is unaffected by the aspect of observation compared to the OCS shown in Figure4a. Here, Figure5b: Probability distribution of DoLP and S. Note that the first and the last 10 ms was excluded in Figure4a. 


\section{Figure 7}
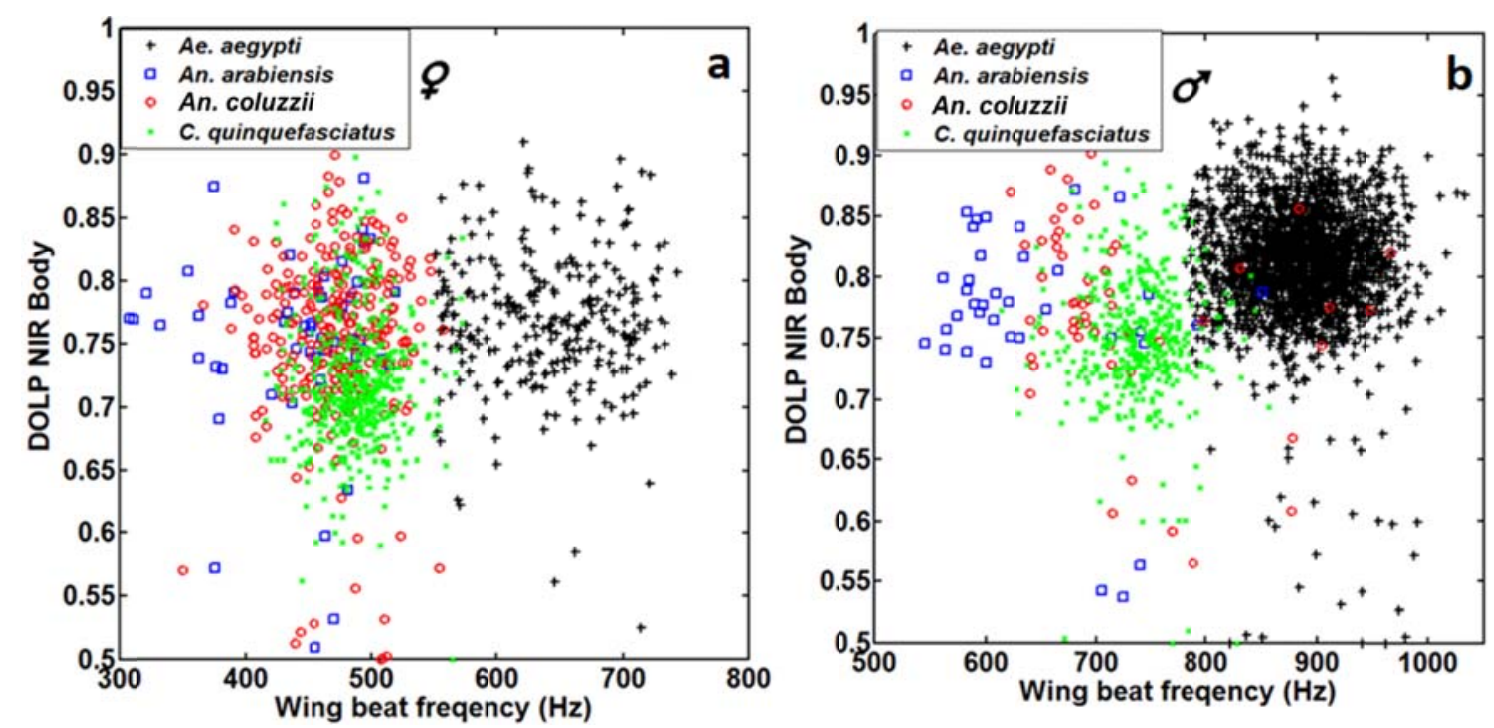

Figure 7: Scatterplot of the WBFs and the NIR DoLP Body of males and females from four different mosquito species. 7a: Female mosquitoes: The WBF distribution of An. coluzzii overlaps with that of An. arabiensis at lower frequencies, and with C. quinquefasciatus at higher frequencies. Ae. aegypti can be distinguished from the others. 7b: Male mosquitoes: the same trends can be observed as for the female mosquitoes. An. coluzzii overlaps with An. arabiensis at lower frequencies and with C. quinquefasciatus at higher frequencies, whereas Ae. aegypti is clearly distinct from the others. 


\section{Figure 8}
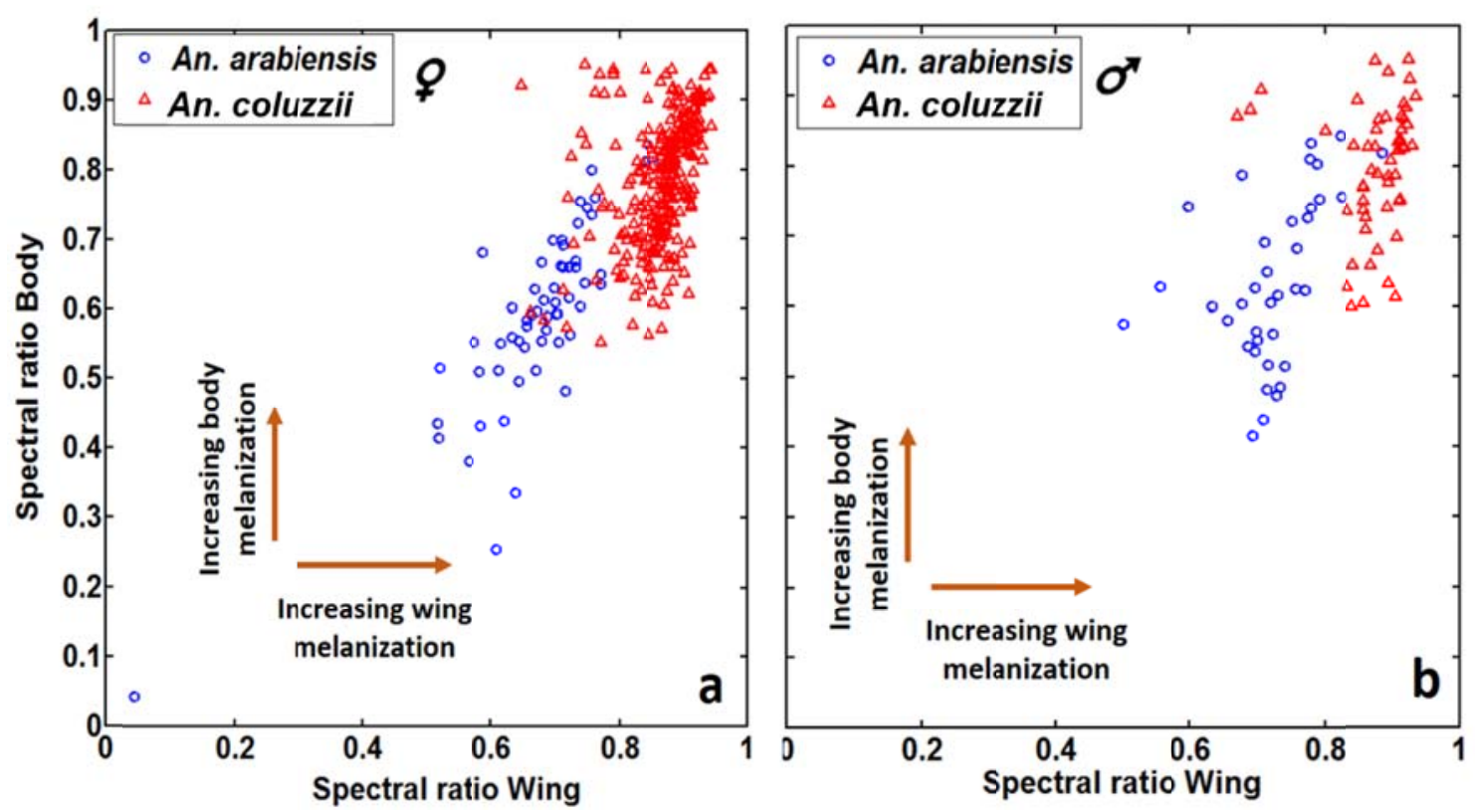

Figure 8: Scatter plot of spectral ratio of bodies and wings of An. coluzzii and An. arabiensis. 8a and $8 \mathbf{b}$ show the $S_{n}$ of female and male malaria mosquitoes, respectively. This figure indicates that body and wing spectral ratio distinguishes the two closest species, which would otherwise have been impossible to differentiate based on their WBF. 


\section{Figure 9}
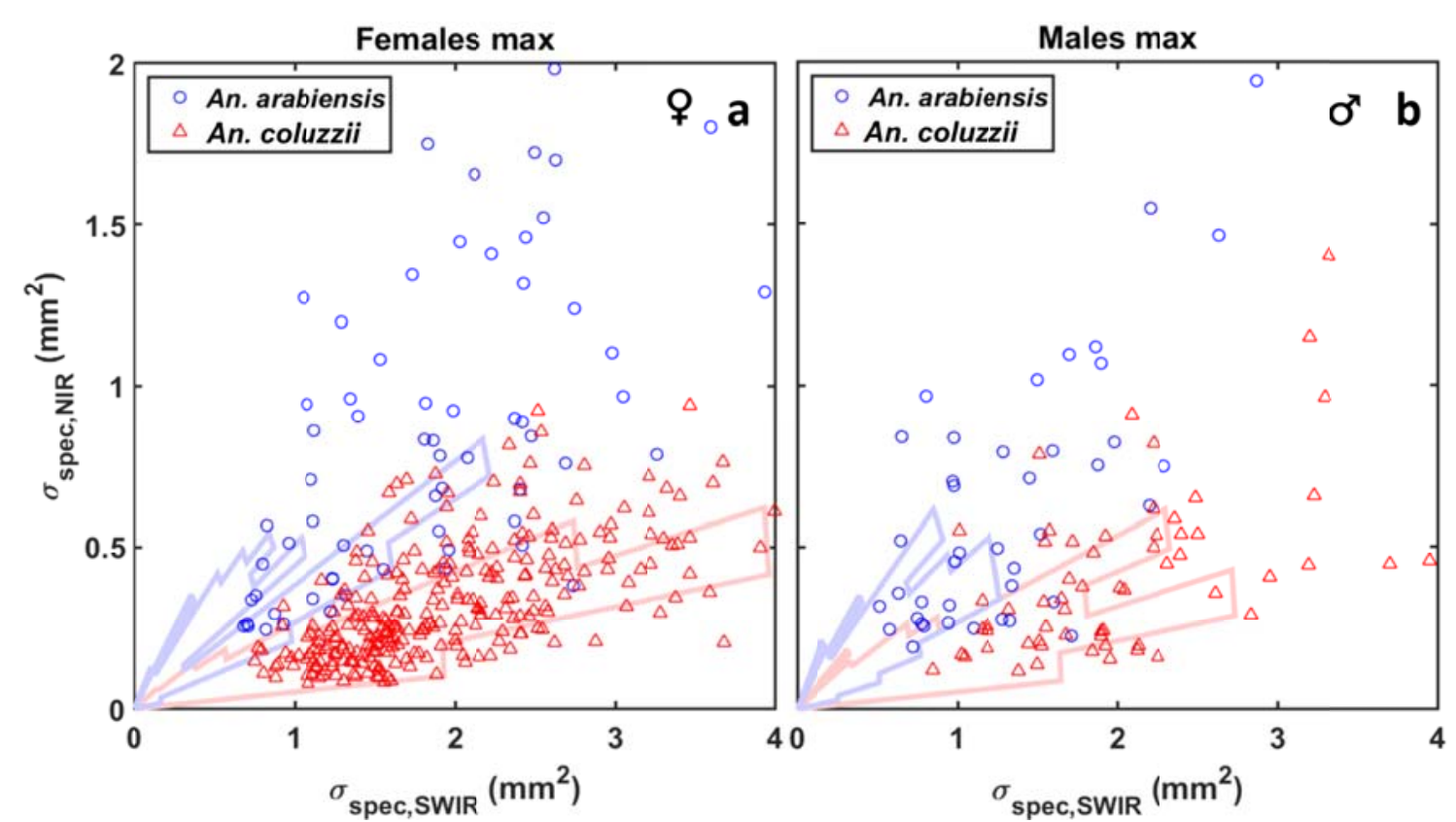

Figure 9: NIR and SWIR cross sections of the single largest specular flash from each observation of malaria mosquitoes (An. coluzzii and An.arabiensis). The faded curves indicate polar histograms for the two species. Despite the large variance in both axes, the species differ significantly in the spectral ratio of the specular reflectance in NIR and SWIR, to the extent that spectral angle differs more than twice the FWHM. When considering the median magnitude of several specular spikes, the discrepancy increases significantly. The relative specular contribution in the two spectral bands is governed by the wing membrane thickness. This parameter distinguishes the two malaria mosquitoes, which otherwise would be impossible to distinguish them based on their $W B F, f_{0}$. 


\section{Table 2}

\begin{tabular}{|c|c|c|c|c|c|c|c|c|c|c|c|c|}
\hline & Species & $\begin{array}{l}N \\
(\#)\end{array}$ & $\begin{array}{c}\text { WBF } \\
\text { NIR } \\
\text { Wing } \\
(\mathrm{Hz}) \\
\end{array}$ & 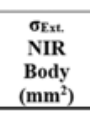 & $\begin{array}{l}\begin{array}{c}\text { DoLP } \\
\text { NIR } \\
\text { Body } \\
\text { (\%) }\end{array} \\
\end{array}$ & $\begin{array}{c}\text { DoLP } \\
\text { SWIR } \\
\text { Body } \\
(\%)\end{array}$ & $\begin{array}{c}\mathbf{R} \\
\text { NIR } \\
\text { Body } \\
(\%) \\
\end{array}$ & $\begin{array}{c}\text { R } \\
\text { SWIR } \\
\text { Body } \\
(\%) \\
\end{array}$ & $\begin{array}{c}\text { S } \\
\text { Ratio } \\
\text { Body } \\
(\%) \\
\end{array}$ & $\begin{array}{c}\text { S } \\
\text { Ratio } \\
\text { Wing } \\
(\%) \\
\end{array}$ & $\begin{array}{c}\sigma_{\text {iprec. }} \\
\text { NIR } \\
\text { Wing } \\
\left(\mathrm{mm}^{2}\right) \\
\end{array}$ & $\begin{array}{l}\sigma_{\text {oppec. }} \\
\text { SWIR } \\
\text { Wing } \\
\left(\mathrm{mm}^{2}\right)\end{array}$ \\
\hline \multirow{4}{*}{ 우 } & An. coluzzii & 279 & $471[53.8]$ & $4.2[2.3]$ & $75[8.2]$ & $78[9.9]$ & $31[27]$ & $98[38]$ & $79[13]$ & $89[6.0]$ & $0.29[0.25]$ & $1.8[0.97]$ \\
\hline & An.arabiensis & 66 & $446[92.5]$ & $7.2[3.2]$ & $75[16]$ & $75[12]$ & 17 [34] & $36[41]$ & 59 [11] & $69[9.1]$ & $0.79[0.79]$ & $1.9[1.3]$ \\
\hline & C.quinquefasciatus & 521 & $488[32.3]$ & $6.3[2.5]$ & $71[6.1]$ & $73[5.2]$ & $30[35]$ & $77[39]$ & $65[19]$ & $82[9.9]$ & $0.44[0.37]$ & $1.5[0.85]$ \\
\hline & Ae.aegypti & 377 & $637[82.6]$ & $5.3[1.2]$ & $77[6.2]$ & $73[5.3]$ & $30[24]$ & $77[36]$ & $75[14]$ & $84[4.1]$ & $0.28[0.18]$ & $0.75[0.53]$ \\
\hline \multirow{4}{*}{$\sigma^{2}$} & An. coluzzii & 60 & 704 [127] & $4.7[2.1]$ & $77[9.0]$ & $79[16]$ & $26[18]$ & $64[30]$ & $83[12]$ & $87[5.2]$ & $0.36[0.31]$ & $1.9[0.81]$ \\
\hline & An.arabiensis & 42 & $621[127]$ & $7.0[2.6]$ & $77[5.1]$ & $78[6.2]$ & $22[28]$ & $32[29]$ & $62[19]$ & $72[8.3]$ & $0.53[0.52]$ & $1.3[0.91]$ \\
\hline & C.quinquefasciatus & 431 & $742[40.6]$ & $6.1[2.1]$ & $75[5.2]$ & $77[7.1]$ & $17[23]$ & $36[26]$ & $71[16]$ & $83[7.2]$ & $0.31[0.28]$ & $1.2[0.66]$ \\
\hline & Ae.aegypti & 2159 & $889[59.7]$ & $5.3[1.3]$ & $81[5.3]$ & $78[7.0]$ & $17[13]$ & $36[16]$ & $71[14]$ & $77[9.9]$ & $0.28[0.18]$ & $0.71[0.38]$ \\
\hline
\end{tabular}

Table 2: Summary of reported values of each sex of the four mosquito. $N$, indicate the number of observations

from random interceptions through probe volume. Observation from each class are merged from several batches recorded different days. The remaining values are within group median with the variance in parenthesis given by the interquartile range (IQR).

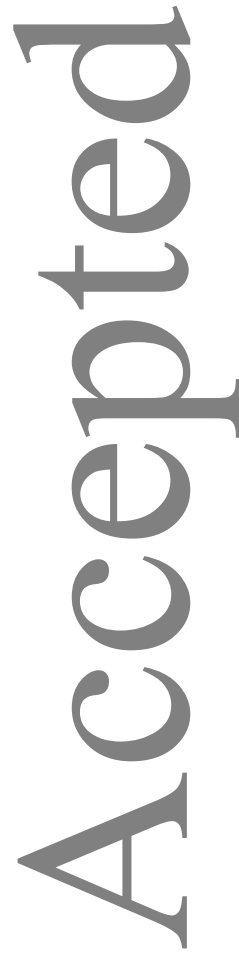

This article is protected by copyright. All rights reserved. 